\title{
Ocular significance of intraventricular haemorrhage in premature infants
}

\author{
Michael O'Keefe, Namir Kafil-Hussain, Ian Flitcroft, Bernadette Lanigan
}

\begin{abstract}
Aim-To document ocular outcome in premature infants with intraventricular haemorrhages (IVH).

Methods-68 preterm infants with IVH were examined.

Results-Mean gestational age was 28.1 weeks (range 24-35). Mean birth weight was $1045.9 \mathrm{~g}$ (630-2240). Mean follow up was 54.6 months $(6-150)$. IVH is graded from 1 to 4 based on the severity of haemorrhages. The incidence of ocular abnormalities was compared between low grade IVH (grade 1 and 2) and high grade IVH (grade 3 and 4). Of the 68 infants with IVH, ROP occurred in 33 infants $(48.5 \%)$; $13(43.3 \%)$ had low grade IVH; $20(52.6 \%)$ had high grade IVH. Strabismus developed in 30 infants $(44.1 \%) ; 14(46.6 \%)$ had low grade IVH; $16(42.1 \%)$ had high grade IVH. Infants with high grade IVH were at significant greater risk than infants with low grade IVH for the development of optic atrophy $(31.5 \%$ v $16.6 \%)$, hydrocephalus $(57.8 \% v 10 \%)$.

Conclusion-This study highlights the serious significance of all grades of IVH with the higher incidence of optic atrophy and hydrocephalus with high grade IVH. (Br f Ophthalmol 2001;85:357-359)
\end{abstract}

Intraventricular haemorrhage (IVH) is a common complication associated with prematurity. ${ }^{1}$ The incidence of IVH increases progressively with decreasing gestational age-for example, from $1.6 \%$ at $38-43$ weeks up to $50 \%$ at 24-30 weeks of gestation. ${ }^{2}$ Despite advances in neonatal critical care, $21 \%$ of infants weighing less than $1000 \mathrm{~g}$ and $12 \%$ of those weighing less than $1500 \mathrm{~g}$ were affected. ${ }^{3}$ Important neurological complications are periventricular leucomalacia and post-haemorrhagic hydrocephalus. ${ }^{4}$

The purpose of this study was to document the incidence and the severity of the ocular morbidity associated with intraventricular haemorrhage in premature infants and to compare the morbidity between low grade and high grade IVH.

\section{Methods}

This consecutive study group consisted of 68 preterm infants born between 1987 and 1998 . Intraventricular haemorrhage was diagnosed and graded by cranial ultrasonography. If clinically indicated, an ultrasound scan was performed before 3 days of age and at the end of the first postnatal week, to establish the maximal extent of the haemorrhage and on a weekly basis for surveillance of ventricular size. All scans were reviewed by a consultant neonatologist. Screening for acute retinopathy of prematurity (ROP) was performed in the intensive neonate units by consultant ophthalmologist (MO'K). Neonates were screened according to the Royal College of Ophthalmologists guidelines. ${ }^{5}$ All infants, born under 30 weeks postconceptual age and/or birth weight under $1500 \mathrm{~g}$ were screened and repeated every 2-3 weeks unless the stage of ROP indicated more frequent examinations.

Clinical findings were documented using the international classification of $\mathrm{ROP}^{6}$ - namely, stage 1 , demarcation line; stage 2 , demarcation ridge; stage 3, extraretinal fibrovascular proliferation; stage 4, partial retinal detachment; stage 5, total retinal detachment. Stage 3 threshold disease was defined as in the Multicentre Trial of Cryotherapy for Retinopathy of Prematurity study ${ }^{7}$ - namely, at least 5 contiguous clock hours or 8 cumulative hours of stage 3 ROP in zone 1 or 2 in the presence of plus disease. Pupil dilatation with phenylephrine $2.5 \%$ and cyclopentolate $0.5 \%$ was followed by indirect ophthalmoscopy using a speculum.

The IVH are graded from I to IV based on the severity of haemorrhage. ${ }^{8}$ Grade 1 is bleeding confined to the subependymal matrix. Grade II is an intraventricular haemorrhage without ventricular dilatation. Grade III is and intraventricular haemorrhage with ventricular dilatation. Grade IV is intraventricular haemorrhage with intraventricular haemorrhage and intraparenchymal bleeding. Low grade IVH is grade I and II and high grade IVH is grade III and IV.

Follow up examinations included visual acuity, orthoptic assessment, cycloplegic refraction, and fundal examination. The visual acuity was assessed using different techniques including fixation patterns, forced choice preferential looking, Sheridan-Gardiner, Kay's pictures, and Snellen acuity, depending on the age and mental ability of the child. Statistical analysis was performed by category on $2 \times 2$ contingency tables using the $\chi^{2}$ test or Fisher's exact test when the expected value in any cell of the contingency table was less than 5 .

\section{Results}

The study consisted of 68 preterm infants with intraventricular haemorrhage-30 with low grade IVH (grade I-II) and 38 with high grade IVH (grade III-IV). Gestation was between 24 weeks to 35 weeks with a mean of 28.1 weeks-28.4 weeks for low grade IVH and 27.8 weeks for high grade IVH. Birth weight
Accepted for publication 19 September 2000 
Table 1 Eye findings in IVH

\begin{tabular}{lccc}
\hline & Low grade IVH & High grade IVH & All IVH \\
\hline Number & 30 & 38 & 68 \\
ROP & $13(43.3 \%)$ & $20(52.6 \%)$ & $33(48.5 \%)$ \\
Significant ROP & & & \\
$\quad$ (stage3 or worse) & $3(10 \%)$ & $8(21.1 \%)$ & $11(16.1 \%)$ \\
Strabismus & $14(46.6 \%)$ & $16(42.1 \%)$ & $30(44.1 \%)$ \\
Optic atrophy & $5(16.6 \%)$ & $12(31.5 \%)$ & $17(25 \%)$ \\
Optic nerve hypoplasia & $4(13.3 \%)$ & $5(13.1 \%)$ & $9(13.2 \%)$ \\
Nystagmus & $6(20 \%)$ & $6(15.7 \%)$ & $12(17.6 \%)$ \\
Hydrocephalus & $3(10 \%)$ & $22(57.8 \%)$ & $25(39.1 \%)$ \\
Cerebral palsy & $9(30.3 \%)$ & $11(28.94 \%)$ & $20(29.4 \%)$ \\
Visual acuity <6/60 & $2(6.6 \%)$ & $5(13.2 \%)$ & $7(10.3 \%)$ \\
\hline
\end{tabular}

was $630-2240 \mathrm{~g}$ with a mean of $1045.9 \mathrm{~g}$ $-1058.2 \mathrm{~g}$ for low grade IVH and $1032.2 \mathrm{~g}$ for high grade IVH. Follow up was between 12-150 months, with a mean of 54.6 months59.2 months for low grade IVH and 50 months for high grade IVH. There were 35 males and 33 females, of which 61 were singletons and seven twins.

Of the 68 infants, acute ROP developed in 33 infants $(48.5 \%)-13(43.3 \%)$ had low grade IVH and $20(52.6 \%)$ had high grade IVH. The overall incidence of significant ROP (stage 3 ROP or worse) in this population of babies was $16.2 \%$ with $21.1 \%$ in high grade IVH and $10 \%$ in low grade IVH. There is no statistical difference between low and high grade IVH.

Of 30 infants with low grade IVH, 14 $(46.6 \%)$ developed concomitant strabismus. By comparison, of 38 infants with high grade IVH, $16(42.1 \%)$ developed strabismus-14 with concomitant strabismus and two with incomitant strabismus. In low grade IVH, 11 had esotropia and three had exotropia. However, in infants with high grade IVH, 12 had esotropia, three had exotropia, one with bilateral superior oblique palsy, and one with downgaze palsy. The difference in the incidence of strabismus between low and high grade IVH was not statistically significant.

Both low grade and high grade IVH were associated with increases in the prevalence of optic atrophy, optic nerve hypoplasia, nystagmus, hydrocephalus, cerebral palsy, and reduced vision. A major difference is the optic atrophy and hydrocephalus being significant complications of grade III and grade IV. Infants with high grade IVH were at significant greater risk than infants with low grade IVH for the development of optic atrophy $(31.5 \% v$ $16.6 \%)$ and hydrocephalus (57.8\% v $10 \%$ ) respectively (Table 1). Three children with optic atrophy had stage 3 or worse of ROP - two with low grade IVH and one with high grade IVH.

\section{Discussion}

Intraventricular haemorrhages originate in the subependymal germinal matrix layer of the developing brain with possible rupture into the ventricular system, ${ }^{9}$ usually in the region of head or body of the caudate nucleus. ${ }^{10}$ This layer gradually decreases in size as the fetus matures and is virtually absent in full term babies. ${ }^{11}$ The haemorrhages are graded from I to IV based on the severity of the haemorrhages. ${ }^{8}$ Ten per cent of the low weight infants had grade III or IV with significantly increased risk of neurosensory handicaps. ${ }^{1}$ Major neurological handicaps were seen in $75 \%$ of children with high grade IVH (defined as grade III and IV) ${ }^{12}$ compared with $16 \%$ of children with low grade IVH (defined as grade I and II). ${ }^{13}$

In this study, 30 children $(44.1 \%)$ developed concomitant strabismus with $46.6 \%$ in low grade IVH and $42.1 \%$ in high grade IVH. This higher incidence of strabismus in low grade IVH was not statistically significant from high grade IVH. Phillips et $a l^{14}$ have shown a strong correlation between severity of haemorrhage and subsequent ocular abnormalities; 38 infants with IVH, strabismus in 14 (37\%), esotropia in $12(32 \%)$, and exotropia in two (5\%). A study by Page et $a l^{15}$ showed that all children with grade III or IV IVH in the neonatal period developed esotropia. Infants with high grade IVH were at significantly greater risk for the development of esotropia than were infants with less severe or no haemorrhage. Tamura and Hoyt ${ }^{16}$ studied 11 premature infants with high grade IVH and noted upgaze palsy, esotropia, and tonic downgaze deviation in all infants. McGinnity and Halliday ${ }^{17}$ found that clinically diagnosed intraventricular haemorrhage is associated with strabismus. King and Cronin ${ }^{18}$ studied 13 premature infants with grade IV intraventricular haemorrhage. They found nearly equal incidence of strabismus in the IVH and control group. The most likely aetiology of strabismus is due to increased intracranial pressure in postintraventricular haemorrhagic hydrocephalus. In our 30 cases, acute increase in intracranial pressure did not account for all cases of strabismus, since the strabismus persisted despite resolution of IVH and control of intracranial pressure. Low cerebral blood flow is another possible mechanism. It is associated with severe intraventricular haemorrhage, and parenchymal injury may result in strabismus. ${ }^{19}$ All of these infants were premature and many had other associated ocular abnormalities such as ROP, optic atrophy, and hydrocephalus. This study confirms a higher incidence of ROP with IVH. There is no statistical difference between low grade IVH and high grade IVH. Procianoy et $a l^{20}$ have shown a statistical association between ROP and IVH. Hungerford et $a l^{1}$ found that ROP was strongly associated with evidence of brain damage, often consistent with hypoxic ischaemic injury. Brown et a ${ }^{22}$ confirmed the strong association of ROP with bronchopulmonary dysplasia, low birth weight, and IVH. Charles et $a l^{23}$ reported IVH to be a significant risk factor for the development of ROP, in addition to low birth weight, short gestation period, and extended supplemental oxygen administration period. However, King and Cronin ${ }^{18}$ and Amato et $a l^{24}$ found no statistical association of ROP and IVH. Phillips et $a l^{14}$ demonstrated that the presence of threshold ROP was not correlated with the presence of IVH in 38 premature infants studied. Perhaps vascular immaturity, hypoxic ischaemic injury, and oxygen free radicals may be the common factors in both conditions. ${ }^{25} 26 \mathrm{Ex}-$ perimental and clinical studies have provided 
compelling evidence for the involvement of oxygen free radicals in the three main disorders of prematurity, chronic lung disease, ROP and IVH. It is proposed that low oxygen tension (hypoxia) followed by periods of reoxygenation is the more likely stimulus for excess oxygen free radicals. ${ }^{27}$ This hypothesis is reinforced by the fact that in immature neonates, the incidence and severity of IVH are highly associated with low Apgar scores at birth. ${ }^{2}$ Our study suggests a doubling of the risk of ROP (stage $3+$ ) in high grade IVH compared with low grade IVH $(20 \% v 10 \%)$, but the study had inadequate power $(<60 \%$ power) to detect a real difference of this magnitude as statistically significant.

This study showed $25 \%$ of IVH children had optic atrophy, particularly significant in high grade IVH. This is much higher incidence than a previous study by Keith and Kitchen ${ }^{28}$ who reported a $2.7 \%$ incidence of optic atrophy in premature infants. Phillips et $a l^{14}$ diagnosed optic atrophy in 10 out of 38 infants with IVH-3/18 (16.6\%) in low grade IVH and $7 / 20(35 \%)$ in high grade IVH. Possible mechanisms of optic atrophy associated with IVH are hypoxia or a direct pressure effect on the optic nerves. ${ }^{29}$ The hypoxic phenomenon of the optic nerves may be similar to the general cerebral hypoxia demonstrated in these infants.

Reduced vision (visual acuity $<6 / 60$ ) was diagnosed in seven infants, with two $(6.6 \%)$ in low grade IVH and five $(13.2 \%)$ in high grade IVH. Harvey et $a l^{30}$ studied visual acuity development in 171 preterm infants with IVH and 73 healthy preterm infants.

IVH subjects had significantly poorer grating acuity, poorer recognition acuity, and smaller average visual field than infants without IVH. However, acuity deficits were not related to the grade of IVH, but may be associated with presence of other ocular abnormalities or cerebral palsy in some IVH subjects. Vohr et $a l^{11}$ found that severe IVH (grade III and IV) is associated with impaired visual motor function, in part because of compression related injury of the periventricular white matter by ventricular dilation. In a study by the Ventriculomegaly Trial Group ${ }^{32}$ of 157 infants with IVH the vision was severely affected in $9 \%$ and $27 \%$ had a field defect.

This study highlights the serious prognostic significance of all grades of IVH. The big difference is the higher incidence of optic atrophy and hydrocephalus with high grade IVH.

1 Gorman WA, Fallon M, Kelly M, et al. The Dublin outcome for low birth infants. Ir Med F 1996;89:186-7.

2 Berger R, Bender S, Sefkow S, et al. Peri/intraventricular haemorrhage: a cranial ultrasound study on 5286 neonates. Eur F Obstet Gynecol Biol 1997;75:191-203.

3 Sheth RD. Trends in incidence and severity of intraventricular haemorrhage. F Child Neurol 1998;13:261-4.
4 Volpe JJ. Intraventricular haemorrhage and brain injury in the premature infant. Neuropathology and pathogenesis. Clin Perinatol 1989;16:361-86.

5 Fielder AR, Levene MI. Screening for retinopathy of prematurity. Arch Dis Child 1992;67:860-7.

6 Report of Joint Working Party. The Royal College of Ophthalmologists and British Association of Perinatal Medicine. Retinopathy of Prematurity: guidelines for screening and treatment. London, 1995.

7 Cryotherapy for Retinopathy of prematurity Co-operation Group. Multicenter trial of cryotherapy for retinopathy of prematurity: preliminary results. Arch Ophthalmol 1988;76: pri-9.

8 Leech RW, Kohnen P. Subependymal and intraventricular haemorrhages in the newborn. Am $\mathcal{F}$ Pathol 1974;77:46575 .

9 Levene MI. Cerebral ultrasound and neurological mpairment: telling the future. Arch Dis Child 1990;65: 469-71.

10 Tarby TJ, Volpe JJ. Intraventricular hemorrhage in the premature infant. Clin North Am 1982;29:1077-104.

11 Burstein J, Papile L, Burstein R. Subependymal germinal matrix and intraventricular hemorrhage in premature infants: diagnosis by CT. Am f Roentgen 1997;128:971-6.

12 Lowe J, Papile L. Neurodevelopmental performance of very low birth-weight infants with mild periventricular, intraventricular haemorrhage. Outcome at 5 to 6 years of age. Am f Dis Child 1990;144:1242-5.

13 Papile LA, Munsick-Bruno G, Schaefer A. The relationship of cerebralintraventricular and early childhood neurologic handicaps. F Pediatr 1983;103:273-7.

14 Phillips J, Christiansen SP, Ware G, et al. Ocular morbidity in verylow birth-weight infants with intraventricular haemin verylow birth-weight infants with intravent

15 Page JM, Schneeweiss S, Whyte HE, et al. Ocular sequelae in premature infants. Pediatrics 1993;92:787-90.

6 Tamura EE, Hoyt CS. Oculomotor consequences of intraventricular haemorrhagesin premature infants. Arch Ophthalmol 1987;105:533-5.

17 McGinnity FG, Halliday HL. Perinatal predictors of ocular morbidity in school children who were very low birthweight. Paediat Perinat Epidemol 1993;7:417-25.

18 King KM, Cronin CM. Ocular findings in premature infants with grade IV intraventricular hemorrhage. $f$ Pediatric Ophthalmol Strabismus 1993;30:84-7.

19 Meek JH, Tyszczuk L, Elwell CE, et al. Low cerebral blood flow is a riskfactor for severe intraventricular haemorrhage. Arch Dis Child Neonatal Ed 1999;81:F15-18

20 Procianoy RS, Garcia-Prats JA, Hittner HM, et al. An association between retinopathy of prematurity and intraventricular haemorrhage in very low birth infants. Acta Pediatr Scand 1981;70:473-7.

21 Hungerford J, Stewart A, Hope P. Ocular sequelae of preterm birth and their relation to ultrasound evidence of cerebral damage. Br f Ophthalmol 1986;70:463-8.

22 Brown DR, Giglan AW, Stretavsky MM. Retinopathy of prematurity: the relationship with intraventricular haemorhage and bronchopulmonary dysplasia. F Pediatr Ophthalmol Strabismus 1990;27:268-71

23 Charles JB, Ganthier R Jr, Appiah AP. Incidence and characteristics of retinopathy of prematurity in low-income inner-city population. Ophthalmology 1991;98:14-17.

24 Amato M, Pasquier S, von Muralt G, et al. Incidence of retinopathy of prematurity in low birth weight infants with peri-intraventricular haemorrhage. Neuropediatrics 1986; 17:191-2.

25 Mylonas C, Kouretas D. Lipid peroxidation and tissue damage. In Vivo 1999;13:295-309.

26 Glass P. Light and the developing retina. Doc Ophthalmol 1990;74:195-203.

27 Kelly FJ. Free radicals disorders of preterm infants. $\mathrm{Br} \mathrm{Med}$ Bull 1993;49:668-73.

28 Keith CG, Kitchen WH. Ocular morbidity in infants of very low birth weight. Br F Ophthalmol 1980;90:234.

29 Volpe JJ. Neurologic outcome of prematurity. Arch Neurol 1998;55:297-300.

30 Harvey EM, Dobson V, Luna B, et al. Grating acuity and visual field development in children with intraventricular visual field development in children with intraventricul
hemorrhage. Dev Med Child Neurol 1997;39:305-12.

31 Vohr BR, Garci-Coll C, Mayfield S, et al. Neurologic and developmental status related to the evolution of visualmotor abnormalities from birth to 2 years of age in preterm infants with intraventricular haemorrhage. F Pediatr 1989; 115:296-302.

32 Ventriculomegaly Trial Group. Randomised trial of early tapping in neonatal posthaemorrhagic ventricular dilatation: results at 30 months. Arch Dis Child Fetal Neonatal Ed 1994;70:F129-36. 